\title{
Thermovision control, interferometry and computer modelling for increasing reliability and quality of electronic products
}

\author{
by Yu.Kofanov, S.Uvaisov ${ }^{1}$ and B.Arlov, G.Pjatnitskaja, A.Segen ${ }^{2}$
}

${ }^{1}$ Moscow state institute of electronics and mathematics (technical university), tel.280-4058, fax.9162807; ${ }^{2}$ State research institute of applied mechanics, Moscow, tel (095)362-4857, fax.(095) 916-2388, Russia

\begin{abstract}
We present information on an automated system ASONIKA that is designed to mainten reliability and quality of radio-electronic equipment (REE) and to simulate physical processes in REE. Methodological aspects are considered to integrate computation and instrumental diagnostics on the basis of the software ASONIKA and measuring thermovision KRIT_T. Formation of the thermal model-norm, utilized for verification of specimens according to their thermal images and evaluation of electronic device reliability and quality under the destabilising influence is suggested. It is noted that a similar technique utilizing holographic interferometry equipment and the mechanical subsystem ASONIKA-M software will allow to generate the model-norm of devices' condition under load.
\end{abstract}

\section{Introduction}

The combination of thermovision systems, optical interferometric devices, acoustic sensors, etc. with computers allows to improve nondestructive testing and defectoscopy technology. Broad application of computer methods do not only concern processing to gauge the visualized primary measuring information, i. e. thermal images, interferograms, holograms, fields of mechanical strains and deformations: Changes take place in the whole process of testing on the basis of computer technology for acquisition, storing, and further utilization of experimental information. This is used, first of all, for the analysis of state and processes, as this is the most complete way to describe objects in various stationary and dynamic modes of operation. Also methods are developed to evaluate probable deviations ("defects") from the accepted normal state. In this sense we see the tendency for growing similiarity on the basis of development of computer methods, instruments, and software for technical diagnostics.

\section{Methodology}

The general methodology is illustrated by the following architecture which contains basic modules of software design and computerized tools for testing and defectoscopy of electronic devices (Figure 3). Application at the stage of designing of the automated system for maintanance of the reliability and quality of electronic units and devices ASONIKA [1] (which consists of the software for study of electrical modes ASONIKA-Q, thermal and mechanical models ASONIKA-T and $M$, combined valuation of reliability and quality ASONIKA-Q) allows to develop a model for the state of an electronic unit or a product. The accuracy of the model depends on initial results of instrumental research and information stored in the ASONIKA database. The model provides a specific or combined model - norm on the state of the electronic product. The model - norm relationship characterizes a reference condition of the product and admissible kinds of deviations, caused by destabilizing factors. The software provides the comparison of a mass-produced specimen with the state defined by the model norm. The specimen verification and product certification for validity in particular is made with respect to the deviation of experimental data from reference data.

Thus the software covers the whole process from the design of a new product up to testing of mass-produced specimens. Moreover, a forecast of a product behaviour during operation can be made. 


\section{Principles of modeling in ASONIKA}

The ASONIKA software simulates various physical processes in REE in a unified way that is processes in REE and approximation of the space in which itrical, thermal and mechanical process description is reduced to the derivation of a sysh it exists. The analytical form of equations with unified parameters and arguments and its comp algebraic and differential analyzed in parametric sensitivity function and, if necessars computing. The derived model is

In order to determine the analytical form for processes description for a device, a topological mode and operation conditions. Such a model is repres taking into account its design, nondirective graphs. Extensive instructive data on epresented in a kind of scheme or construction units (included into database and from modeling of processes in elementary processes in REE devices) is useful for the equipment design

Figure 2 shows the example of thermal modeling: the image of a device with a printedcircuit-board $(2 \mathrm{a})$ and a topological model $(2 \mathrm{~b})$ describing a thermal process. The upper parts
of the topological model correspond to heat generating branches characterize heat exchange with their numb and dissipating elements. Graph evaluated temperature distribution in single elements is also corresponding to the type. The

The uniform methodology in ASONIKA permits to link together different subsystems ( $E$ $-{ }^{T},-M,-Q$ ) and to develop some new subsystems. The new software ASONIKA_ET, _TM provides for the optimization of a model with respect physical processes in a device and ASONIKA-Q allows to estimate quality and reliability of to influencing factors. The subsystem two modules: i. e. "Stability" and "Reliability". The "Stability" quality. It is designed to examine the influence of one module performs the evaluation of destabilizing factors (e.g. scattering of technological or several technological or in-service materials degradation; changes in cooling conditions or lameters of radioelectronic elements; the evaluation of industrial availability of the product in character; irradiation effect). Here specimens which need no adjustments, is carried in percentage of defect-free output evaluates the degree of reliability of a device according to well. The "Reliability" module failure of a device in view of gradual or sudden failures $[1,2]$.

\section{Aspects of integration and application of software-hardware tools}

\subsection{Software and equipment at tests}

Let us consider integration of software-hardware tools for thermal modeling and and technical diagnostics for thermovision inspection. The main tool for computer modeling was performed with the computer measuring thermovision an auxiliary role. Diagnostics was software for processing and analyzing of thermal images [3] KRIT_T. It uses advanced employs a well-known and in Russia widely utilized IR cam [3]. The thermovision KRIT_T thermography of printed-circuit-cards in devices of tower and "Raduga". It was applied for modules and microassemblies and surfaces of optoeler and single-block design, cases of computerized thermovision microscope on the basis of AGA units of precision devices. A the thermography of small objects, e.g. microcircuits andics $\times 15$ zoom was utilized for elements of non-hermetic assemblies, etc. Additionally holog other semiconductor devices, in some cases to analyze mechanical strain.

\subsection{ASONIKA_T: thermal models of REE}

The ASONIKA_T software description is presented in detail [1]. We shall consider some features of development of thermal models for REE and problem of accuracy. 
ASONIKA_T realizes computer technology of reliable thermal modeling of equipment for various purposes, design and level of integration [4]. ASONIKA_T automatically designs topological models of thermal processes and gives their numerical solution for such designs as cases and and racks, cassette and tower blocks, hybrid assembly modules, printed-circuit units, microassemblies, functional cells and radiators of several types. In other cases manual design of topological models for further utilization by software is required. In both cases the ASONIKA_T advanced database is used. A user chooses the type of model, thermotechnical characteristics of materials and formalized topological sample models for elementary design units forming thermal process topology for a device. Topology development and model calculation for devices of complex design are performed step by step using the hierarchical principle, i.e. from external bearing designs (case, rack, block case) to internal parts (printedcircuit unit, module, element). Thus external thermal condition and design determine the boundary conditions for internal units. The accuracy of modeling of temperature distribution in elements and location areas of internal units depends basically on the correct choice or manual design of topological models: The problem involved is adequacy of model heat dissipation and cooling conditions, thermotechnical parameters for materials and elements to real conditions and parameters in the device. In practice the accuracy in the case of automatic monitoring of temperature in an internal unit (e.g. printed-circuit card) is usually not worse than $30 \%$. It attains 5-10\% for improved developed models [1]. In the case of manual modeling that requires some skill from a user, there is a risk of an error, and the same accuracy is attained with more effort.

The use of thermography for thermal modeling contributes to the reliability of developed models. A comparison of simulated thermal conditions with experimental results obtained by thermography on the same microcircuit was performed $[4,5]$. Within the temperature range of $25-55^{\circ} \mathrm{C}$ the agreement was $3-5 \%$. To obtain this result we coupled the thermovison system to absolute temperature with an accuracy $0,2^{\circ} \mathrm{C}$ by using a certified point-contact thermometer (when the contact to a surface was possible) or with an accuracy of $0,5^{\circ} \mathrm{C}$ by a black body reference source (when the contact was impossible). On black surfaces the noise equivalent temperature difference (NETD) was $0.1-02 .{ }^{\circ} \mathrm{C}$.

\subsection{Specimen certification and defectoscopy}

The thermal model developed and accepted as a norm provides an opportunity to verifiy mass-produced specimens for thermal conditions, in particular, for drawing up a certifcate of a product. From this point of view a thermal certification system for electronic products may be described by the scheme in Figure 1. Here the comparison of real and reference fields is performed by comparison of the thermal image of a mass-produced specimen and the graphic model of surface thermal distribution, in which the admissible deviations for elements have also been introduced. If there is a reference specimen with its definite thermal normal image, it may be compared also. The comparison in the KRIT_T software is performed with built-in options for subtraction and imaging of differences from the preset reference thermal image. In this case a graphic thermal model may be used. There are also options to select elements or areas of interest from a thermal image of a multielement electronic unit surface and compare their temperatures with the preset numerical norm.

KRIT_T automatically determines the noise level in the case of comparison in the field with small temperatures. Introduced thermal images are allowed with scale gradation not below noise level.

The decision on the validity of a specimen (Figure 1) is made according to a preset criterion of the type "valid / invalid" or "valid / implicit defect / invalid". The verification of a group of specimens is performed in a similar way in other cases, too. It is possible to determine technological scattering of specimen parameters, analyze some defects in specimens, etc. 


\subsection{Optimization, quality, reliability}

In addition to the main module ASONIKA_T designed for thermal modeling, other subsystems of ASONIKA can be used, thereby expanding the field where the method can be applied. The opportunities may be seen clearly from the scheme in Figure 4 . Once an authentic thermal model - norm is created under conditions and modes accessible for thermography, we can extend this model to situations when there is no access. There are additional options: ASONIKA_ET - allows to optimize the output parameter of the device electrical mode when thermal conditions change; ASONIKA_MT - allows for optimization of thermal conditions stipulated by mechanical effects such as vibration; ASONIKA_ETM - takes into account both of these influences. Table 1 indicates some examples of different ASONIKA tools and thermography.

Table 1. Examples of thermal modeling using thermovision inspection and software

\begin{tabular}{|c|c|c|c|}
\hline$N$ & Condition for sofiware model-norm & New conditions for corrections of model & Software \\
\hline 1 & $\begin{array}{l}\text { Thermovision control under } \\
\text { normal arnbient conditions }\end{array}$ & $\begin{array}{l}\text { Operation temperature, which is not } \\
\text { supplied by thermovision inspection }\end{array}$ & ASONIKA_T \\
\hline 2 & $\begin{array}{l}\text { Non-hermetic micro-assembly } \\
\text { without a cover }\end{array}$ & $\begin{array}{l}\text { Covered hermetically sealed } \\
\text { microassemply }\end{array}$ & ASONIKA_T \\
\hline 3 & $\begin{array}{l}\text { Mutual influence of electrical and } \\
\text { thermal modes is discounted }\end{array}$ & $\begin{array}{l}\text { Taking into account mutual influence of } \\
\text { electrical and thermal modes with } \\
\text { optimizing the electrical mode of } \\
\text { operation }\end{array}$ & $\begin{array}{l}\text { ASONIKA_ET with } \\
\text { data transfer from } \\
\text { ASONIKA_E and_T }\end{array}$ \\
\hline 4 & $\begin{array}{l}\text { Mechanical process (vibration) } \\
\text { effect on heating is not taken into } \\
\text { account }\end{array}$ & $\begin{array}{l}\text { Influence of vibration on thermal } \\
\text { conditions taken into account }\end{array}$ & $\begin{array}{l}\text { ASONIKA MT with } \\
\text { data transfer from } \\
\text { ASONIKA M and } T\end{array}$ \\
\hline 5 & $\begin{array}{l}\text { Thermal imaging of specimens for } \\
\text { comparison with the norm }\end{array}$ & $\begin{array}{l}\text { Technological scattering of } \\
\text { temperatures taken into account to } \\
\text { estimate validity of technology }\end{array}$ & $\begin{array}{l}\text { ASONIKA_K with data } \\
\text { transfer from } \\
\text { ASONIKA_ } T\end{array}$ \\
\hline
\end{tabular}

This article cannot describe details of particular techniques for different problems within the methodology of application of ASONIKA tools and thermovision inspection.

\subsection{Other applications}

Similar systems based on precise computerized holographic interferometers and ASONIKA_M software are under development now. They are designed for the analysis and certification of electronics parts as well as optical and mechanical devices taking into account mechanical strain and deformation caused different kinds of mechanical loads: i.e. vibrations, impacts, etc.

\section{Conclusion}

The development the thermal modeling on the basis of ASONIKA platform with advanced thermovision system as a software-hardware combination opens new horizons for design and nondestractive control for increasing quality and reliability of electronic devices.

\section{REFERENCES}

[1] Application of an automated system of maintenance of reliability and quality. Under edition by KOFANOV (Yu.). Moscow, Moscow state institute of electronics and mathimatics (technical university), 1993, $212 \mathrm{p}$.

[2] KOFANOV (Yu.) - Theoretical aspects of constraction, technology and reliability of radioelectronic equipment. Moscow, R \& C ed., 1991; 360 p.

[3] PJATNITSKAJA (G.), SEGEN (A.), SEMENNICOV (A.), TICHOMIROV (S.) - Computer measuring thermovision for technical diagnostics KRIT_T. Proc. Conf. Urgent Problems of the Analisis and Maintenance of Reliability and Quality of Devices. Pensa, May 26-29, 1996. 


\section{http://dx.doi.org/10.21611/qirt.1996.065}

[4] KOFANOV (Yu.), PJATNITSKAJA (G.), SEGEN (A.), UVAISOV (S.) - Thermovision control and modeling of a thermal condition of microcircuits. In transaction "Digital models in designing and technology REA". Pensa state technical university, 1996, p. 96-101.

[5] KOFANOV (Yu.), UVAISOV (S.); ARLOV (B.), PJATNITSKAJA (G.), SEGEN (A.) Software-instrumental means for increasing reliability and quality of electrinic products. Proc. Conf. Information Technology in Design. Moscow, July 1-5, 1996, p.180-183.



Fig. 1. Thermal certification scheme for electronic products


$2 c$

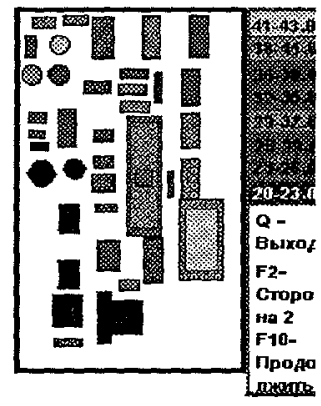

Fig. 2. Example of thermal modeling of an electronic device 


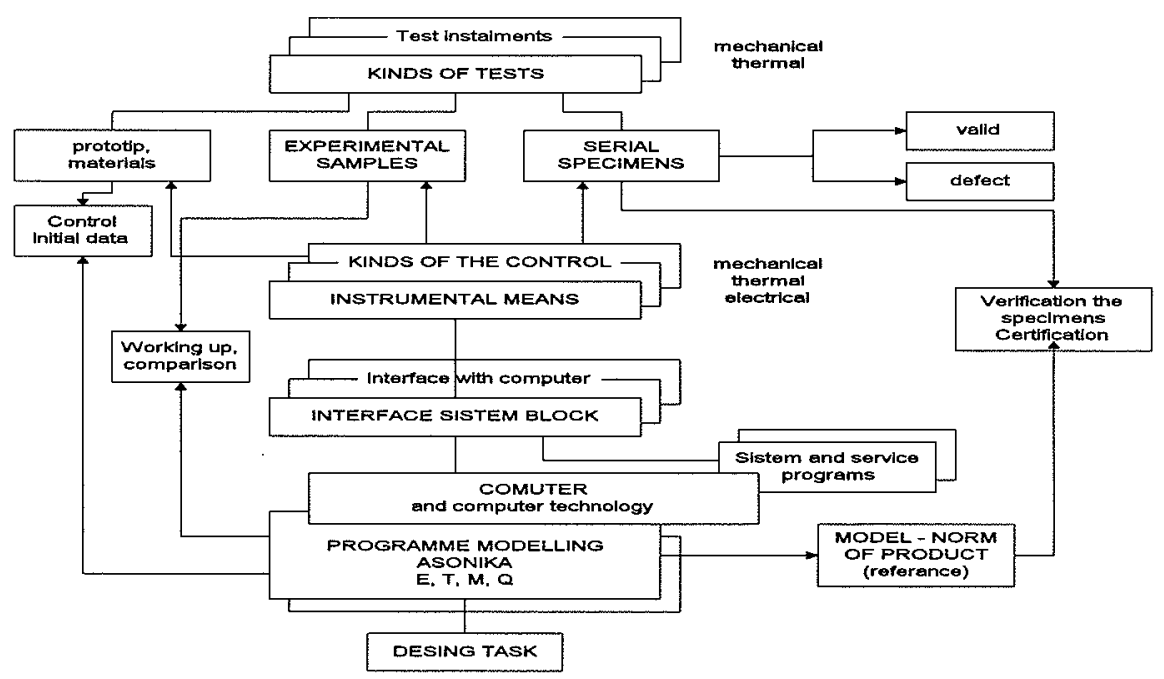

Fig. 3. Architecture software-instrumental means for nondestructive control and defectoscopy electronic units and devices

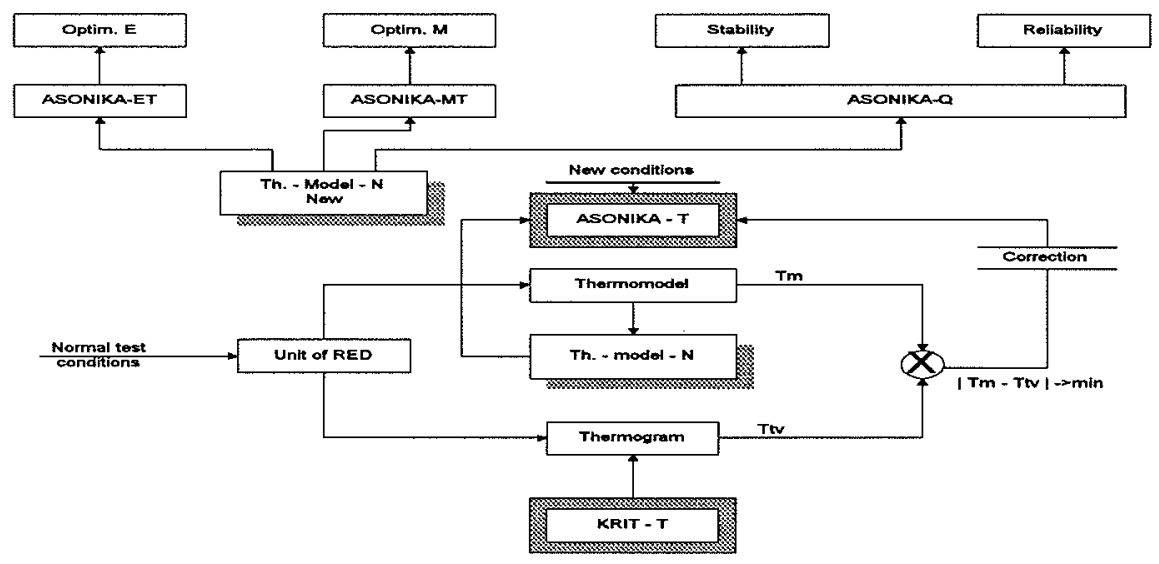

Fig. 4. Complex circuit of serial prodacts reliability designing 